\title{
RHYTHMS AND OTHER BIOLOGY OF THE GIANT TROPICAL ANT PARAPONERA ${ }^{1}$
}

\author{
By Elwood S. McCluskey ${ }^{2}$ and William L. Brown, Jr. ${ }^{3}$
}

\section{Introduction and Field Rhythm}

In January, 1960, the authors were associated in a survey of the ants of Barro Colorado Island, Canal Zone. A nest of Paraponera clavata (Formicidae: Ponerinae: Ectatommini) was located at the base of a I-dm tree by a flashlight search of trees after dark. One of us (ESM) studied the rhythmic activity of ants from this nest in the field, then later in the laboratory. There have not been many laboratory studies of rhythms in social insects. This makes it important to present the results here, even though only a limited number of ants could be observed.

Near dusk, workers were seen in the entrance of the nest. They soon began emerging, so that by the time it became almost too dark to see, a good column extended a meter up the trunk and from there along a vine to adjacent saplings. Night counts were made by dim red flashlight. Figure I shows the number out on the trunk and vine within $2 \mathrm{~m}$ of the nest, as well as the number per minute passing a given point on the vine. Foraging apparently continued through the night, though no observations were made from oloo through 0500 . By an hour or so after dawn the number of workers out had dropped to zero, and only rarely was one seen until the next dusk.

One male appeared in the entry one evening at I 830 just before it became too dark to see in without a light. Winged females were seen elsewhere at a light at night. Bequaert (1926) says "the males appear to be nocturnal and are frequently attracted by artificial light."

We knew the reputation of this ant as a fierce stinger (see Hermann and Blum, 1966, for review). Nevertheless, one of us (ESM) got stung one evening while kneeling beside the nest making counts. The sting entered the leg below the knee through the stretched cloth of field trousers, and for the next two hours the leg felt as though it had been struck by a heavy club.

\section{Culture and Other Observations}

Later we dug out the nest under the base of the tree to a depth of

\footnotetext{
${ }^{1}$ An abstract of a part of this work was given by McCluskey (1964).

'Departments of Physiology and of Biology, Loma Linda University, Loma Linda, CA 92354

${ }^{3}$ Department of Entomology, Cornell University, Ithaca, N.Y. 14850

Manuscript received by the editor November 15, 1972
} 


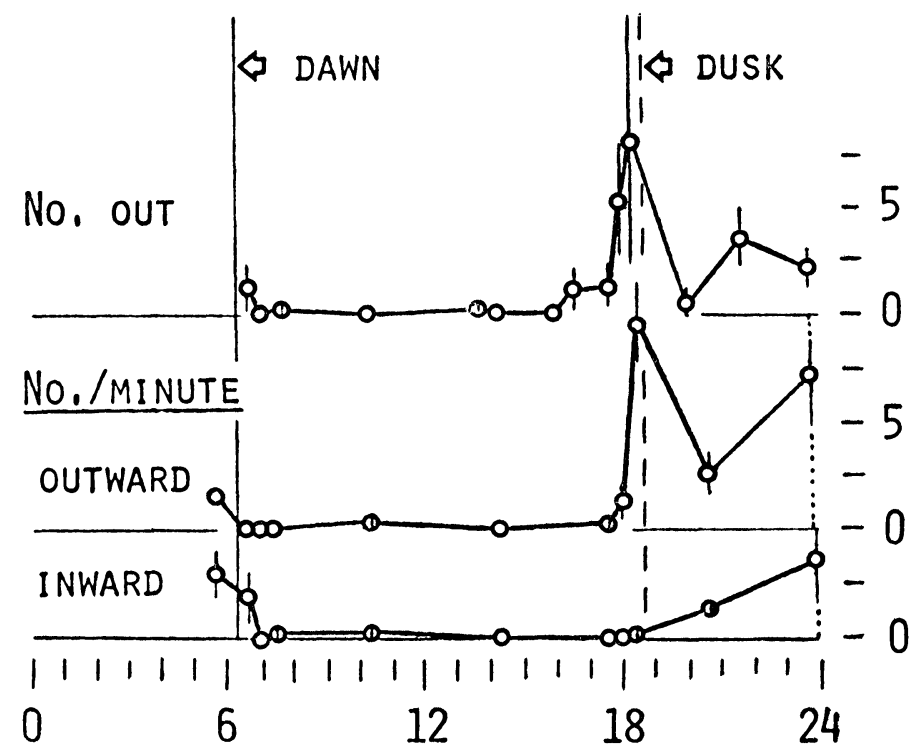

Fig. 1. Worker rhythms, field nest. No./Minute passing each way, and No. Out (only near nest, not total out foraging). Means $\pm S E$ are based on 2-4 days (Jan. 11-21) for No. Out, and on 2-3 days (Jan. 19-21) for No./Minute; thus $\mathrm{N}=2-4$, except for the midnight No./Minute points based on only 1 night (infinite SE shown by dotted line). One-way analyses of variance (ANOVA's) indicate the various hours of day to differ: Outward, $\mathrm{P}<.001$; Inward, $\mathrm{P}<.01$; No. Out, $\mathrm{P}<.30$ (not significant). Dawn and dusk lines drawn at times when first or last barely light enough to see ants.

a half meter, but failed to reach the heart of the nest, since we found no queen, pupae or eggs. Buckets of water were used in a futile attempt to drown the ants out. About ten half-grown larvae were seen and collected, as well as several winged males and females. Three to four hundred workers were collected, and at least another hundred were seen. Bequaert (1926) mentions a nest that contained 500 workers. Mann (1916) says the colonies are small.

We placed the ants one by one with forceps into tall narrownecked bottles. The man who stood guard and held the bottle not only kept the lid poised for immediate capping, but also kept the ants shaken down from near the top; because, unfortunately, though $2 \mathrm{~cm}$ long the ants could climb the glass readily. For transport they were put into a gallon jar mostly filled with leaves. 
Upon return to Harvard the ants were placed in a glass-covered wooden box $\mathrm{I} \mathrm{m} \times 0.6 \mathrm{~m} \times$ o.I $\mathrm{m}$ deep in E. O. Wilson's laboratory. In the box was a nest chamber made by Wilson (1962), with inside diameter of about $2 \mathrm{dm}$ and depth of $2 \mathrm{~cm}$; constant moisture was applied on the center of the nest floor by a large wad of cotton serving as a wick from a continuous column of water through a tube from a bottle outside the box. The ants were offered mealworms, roaches, Drosophila cultures, egg yolk, and sugar water, the last being taken the most readily. There was much restless activity. Mortality was high, so that after a month or two there were only about ten workers and one larva left. None of the larvae matured noticeably.

Efforts were made to get a dealate queen that had been taken near a light on Barro Colorado Island to start a colony. First she was put into a small lucite nest, but with little success. Then several of the larvae from the above described colony were placed with her, and she seemed to accept them. They appeared to remain in good condition for several weeks, but did not mature. When single workers were placed with her she grabbed them with her mandibles and hung on continuously. Later she was confined in a petri dish with Io workers for two days; there was then seeming harmony, so she was put in with the main group of workers. There was no hostility evident; but neither was there progress in colony formation. When most of the ants had died, she and the remainder were put into an aquarium half full of moist earth. They tunneled incessantly; a few survived several more weeks.

In the field we had seen workers descending the branches with liquid droplets suspended between their mandibles, as has been reported by Weber (1946) for another ant in the same tribe, Ectatomma tuberculatum. Honeybees manipulate nectar with their mouthparts when concentrating it. At the same time enzyme from the bee digests sucrose in the nectar. It was therefore of interest to check for digestion of these droplets by Paraponera. This was done by Nevin Weaver and E. O. Wilson in Wilson's laboratory, and they kindly made available the following unpublished results:

One-molar sucrose was presented to the ants in a capillary tube. They held the solution between their mandibles, definitely agitating it with their glossae (egg yolk became frothy under the same conditions). Though the droplets slowly disappeared, they were not noticeably smaller until after $40 \mathrm{~min}$. Of the six ants left undisturbed until the end of $2 \mathrm{hr}$, only one still had a droplet large enough for sampling. A droplet of solution was removed with a capillary from 


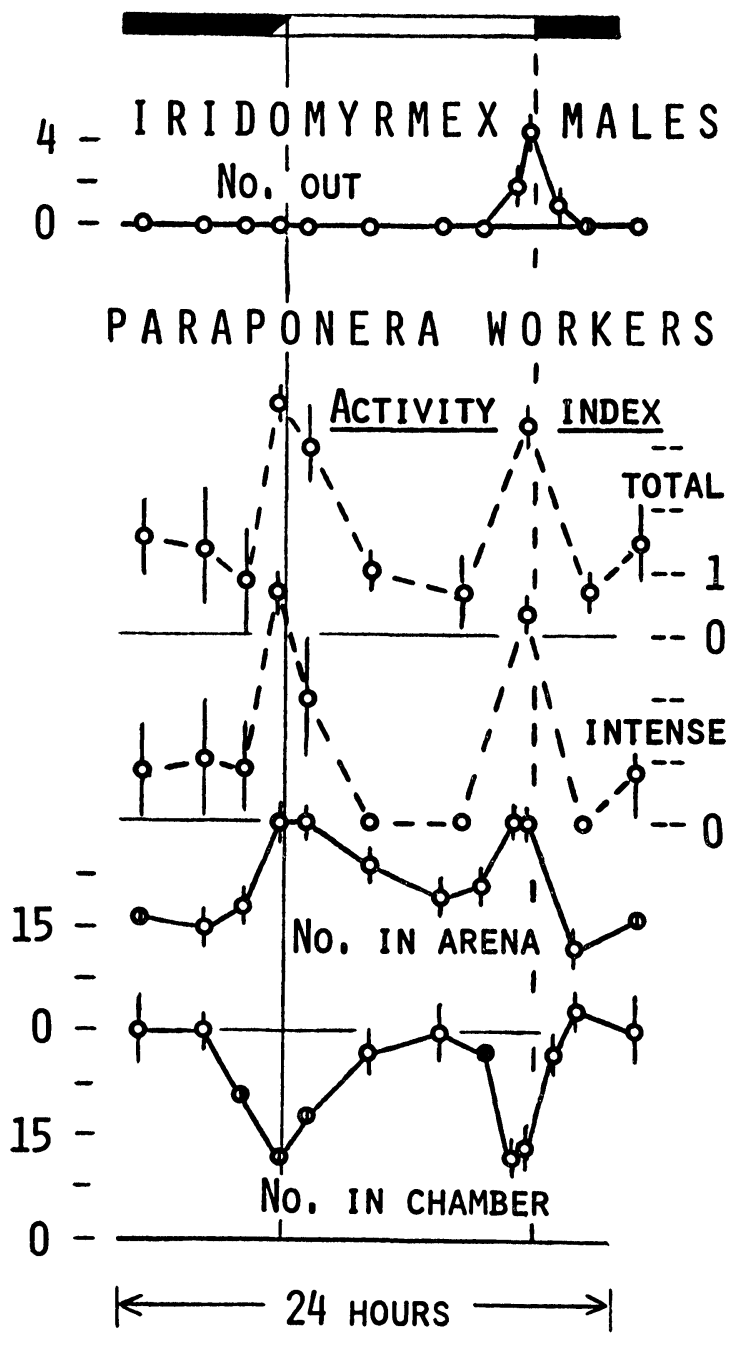


between the mandibles of one ant after $40 \mathrm{~min}$, from another at I $\mathrm{hr}$, and from the final one at $2 \mathrm{hr}$. Each of the three samples was chromatographed on a paper strip. Only sucrose could be detected, indicating that there had been no digestion.

\section{Rhythms in Room Conditions}

The main laboratory lights were on from 0800 to 2000 . There was very dim artificial light in the distance during the night. The temperature of the laboratory was relatively stable $\left(25-30^{\circ} \mathrm{C}\right)$.

The whole box including the nest chamber was darkened, and a tube led to an arena box of equal size exposed to the light-dark cycle. Figure 2 shows the number of workers at each time of day in the arena and in the nest chamber. Also plotted is the level of activity ("activity index") at each observation. Both the number in the arena and the level of activity reached a peak twice a day: just before the lights came on (a little light entered around the window shades for an hour or two before the lights came on), and during the last hour before the lights went off. At the times of peak number out in the arena, the ants were also the most active, running about the box and even jumping - a striking sight.

For comparison is shown the prominent rhythm of appearance outside the nest of male Argentine ants, Iridomyrmex humilis. They were from a colony of Wilson's elsewhere in the same room on the same days. Males of this species come out only during the last of the light period, as previously shown for another colony (McCluskey, I958).

\section{Rhythms in Controlled Conditions}

Some of the ants were transferred to a darkroom for observation in constant temperature (Feb. 3-Mar. I I , $27^{\circ} \pm \mathrm{I}^{\circ} \mathrm{C}$; Mar. I2-Apr. I, $28^{\circ} \pm \mathrm{I}^{\circ} \mathrm{C}$ ) and more completely controlled lighting. There was fluorescent light, 400 lux, for I2 hours daily; clear ruby light dur-

Fig. 2. Worker rhythms, room conditions (also, at top of figure, Iridomyrmex male rhythms elsewhere in same room). One nest containing 50 Paraponera workers. Means \pm SE are based on 3-5 days (Feb. 4-19) for Activity Index, and on 3-8 days (Feb. 3-19) for No. in Arena or Chamber (3-5 days, Feb. 4-18, for Iridomyrmex). ANOVA's give $\mathrm{P}<.001$ for each rhythm shown. To give a more complete picture, first count after midnight is repeated in each case. "Dawn" (solid) and "dusk" (dashed) lines show when room lights were turned on and off. Activity Index: 4, very active or jumping; 3 , active; 2 , moderate; 1 , fairly slow; 0 , slow or quiet ("intense" includes only levels 4 and 3 ). 


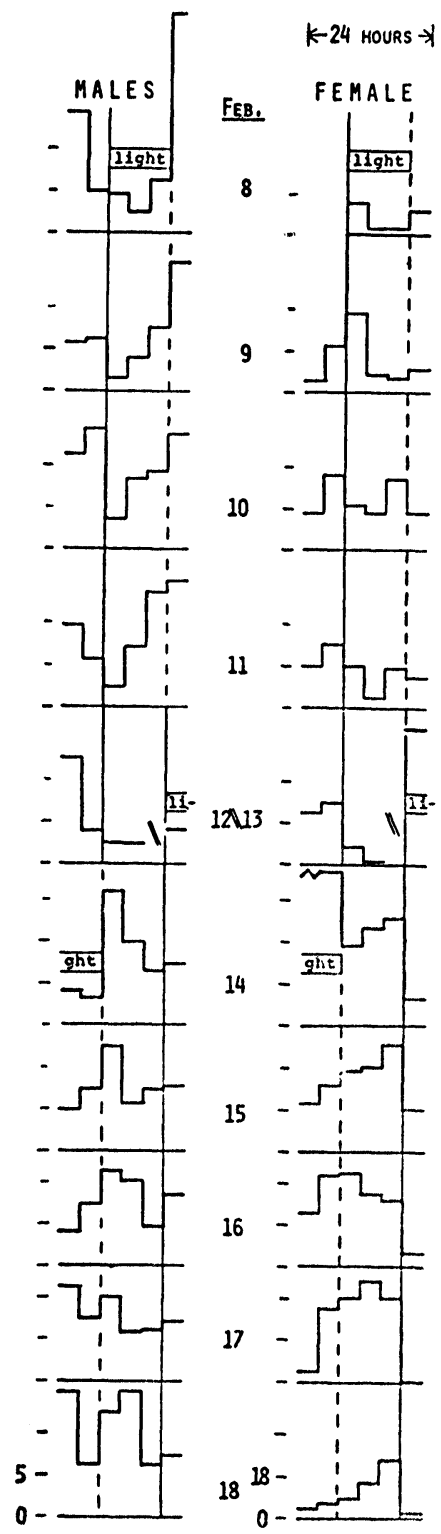


ing the dark hours and continuously during the constant darkness (DD) that followed the days of alternating light and darkness (LD). Counts were not begun until the ants had been installed for at least a day, as well as in the appropriate LD cycle for many days.

Ants were placed in a circle of clear plastic tubing that included at one point a clear plastic chamber with cotton-plugged test tubes of water and of sugar water inverted through its roof. The chamber, with tubes, was covered with an orange plexiglass box to simulate the darkness of a natural nest (McCluskey, 1963). An adjacent capacitance-operated relay recorded each pass of an ant through a certain point ("tunnel") in the circle of tubing.

In these LD conditions a group of three males in one unit displayed a prominent activity rhythm, the highest counts being in the first part of the dark period (Fig. 3 and $5 \mathrm{~A}$ ). Another counter assembly became available to obtain records for a single winged female simultaneous with the last day of LD for the males (Fig. 3 ). There was almost no female activity during the middle of the light period, as shown more fully later (Fig. 5B). The rhythms of the males and of the female both appeared to persist for several days of DD following (Fig. 3). Then the light was turned back on once for 12 hours but 2000-0800 instead of 0800-2000 as during the LD before DD. What appears to be a corresponding shift in phase of the ant rhythms is seen; e.g., the original "daytime" lows now became the highs.

Nearly a month later it was possible to get a more complete LD record followed by another DD series for the same female (Fig. 4). In this case spot eye observations of the activity level were made also, shown by the curve under the histogram. This rhythm is seen to be a close match for the machine-monitored one. The highest activity occurred before and after dawn and dusk, with no activity during midday. Again there was evidence for persistence of rhythm

Fig. 3. Persistence of rhythm in male and in female in DD. Number of passes per hour (4-hr ave) through tunnel. One group of 3 males in a nest, 1 winged female in another unit. Successive days shown one below the other: LD, days preceding and including Feb. 8; DD, Feb. 9-12 and 15-18; hours of light shown by open bars Feb. 8 (0800-2000) and Feb. $13(2000)-14(0800)$. Dawn line (solid) and dusk line (dashed) are continued down through days of DD merely as a point of reference. The LD high of males at beginning of night seems to persist in DD, with a shift to morning after exposure to light through night of Feb. 13-14. The characteristic morning drop in LD activity of female (see also Fig. 5B) seems to persist here in DD, with a shift to evening drops after the night light: Feb. 13-14. 


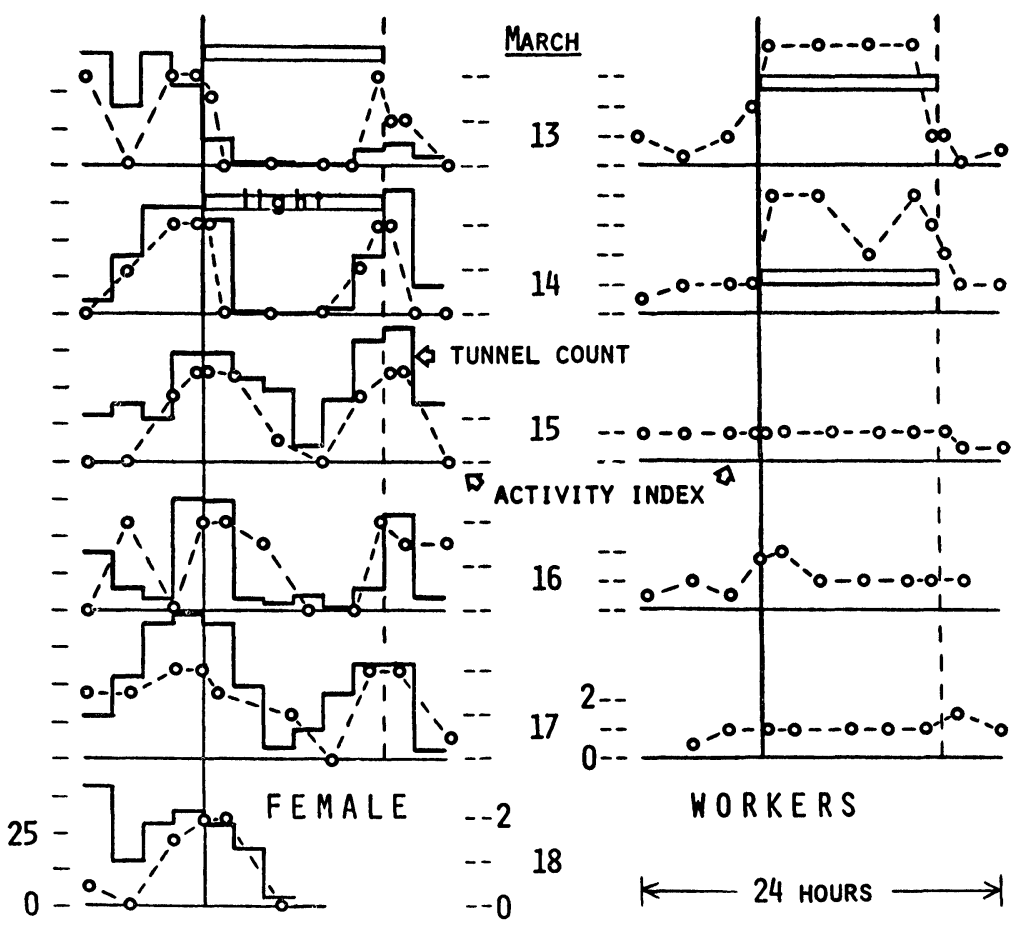

Fig. 4. Rhythms of female and of workers, with persistence in female. Open bars show hours of light on last days of LD (Mar. 13-14); DD thereafter. FEMALE: Same ant as in Fig. 3; Tunnel Count per hour (2hr ave) (histogram), and Activity Index (2, active; 1, walking or other moving; 0, quiet); note prominent morning drop in activity, and persistence in DD. WORKERS: One group of 10 in a 2-chambered nest; Activity Index (4, very active; 3 , active; 2 , moderately active; 1 , slow; 0 , quiet); note high activity level through day and low at night, and seeming lack of persistence in DD (ants plugged connecting tube with cotton March 18, preventing record then). 
in $\mathrm{DD}$, here through two different types of assay. Internal timing is implied in LD by the rise before dawn or dusk signals (Fig. 4 and $5 \mathrm{~B}$ ).

At the same time a group of 10 workers in one two-chambered nest were observed by eye. Each chamber was a clear plastic box about $10 \mathrm{~cm}$ in diameter and depth. One chamber was darkened and had water and sugar water provided; the other served as an arena, dry and fully exposed to the light cycle. The activity level was high during the light period, and low during the dark period (Fig. 4 and $5 \mathrm{D}$ ). The simultaneously-observed rhythm of number out in the arena was similar in form, though less prominent (Fig. $5 \mathrm{D})$. There was no evidence of persistence of activity rhythm (Fig. 4) or arena rhythm (not shown) in DD, though the data are too brief to be conclusive.

When either capacitance counter assembly became available, a single worker was placed in it for counts. This was done for three different individuals. There were problems, such as the ant pulling out the cotton from one of the tubes and flooding the chamber. Fig. ${ }_{5} \mathrm{C}$ combines all the records that were obtained when the conditions were tolerably satisfactory. There appear to be peaks of activity during the first and last parts of the light period.

\section{Discussion}

It should be stressed that conclusions apply only to the particular specimens studied, since replication consisted mainly of different days for the same ant or group, rather than of separate ants or groups.

In the field in January the ants of this colony were crepuscular and nocturnal in their appearance outside the nest (Fig. I). In room conditions the workers appeared out in the arena especially around laboratory dawn and dusk, and their activity level also peaked strikingly at these two times (Fig. 2). In LD there were moderate tunnel activity peaks at the beginning and end of the light period, but, surprisingly, number out in the arena and especially activity index were both much higher through the light period than the dark (Fig. 5D). Why this contrast with the field, where the ants were not seen out during the day?

Among other possibilities, several suggest themselves. The ants were in extremely artificial nests - no dirt, no queen, etc. There was less of a temperature cycle in the laboratory than outside, and the light was dimmer than even in the forest conditions. Further, the gradual dawn and dusk of the field might be important in phasing the activity, as it is in certain mammals (Kavanau, 1967). 


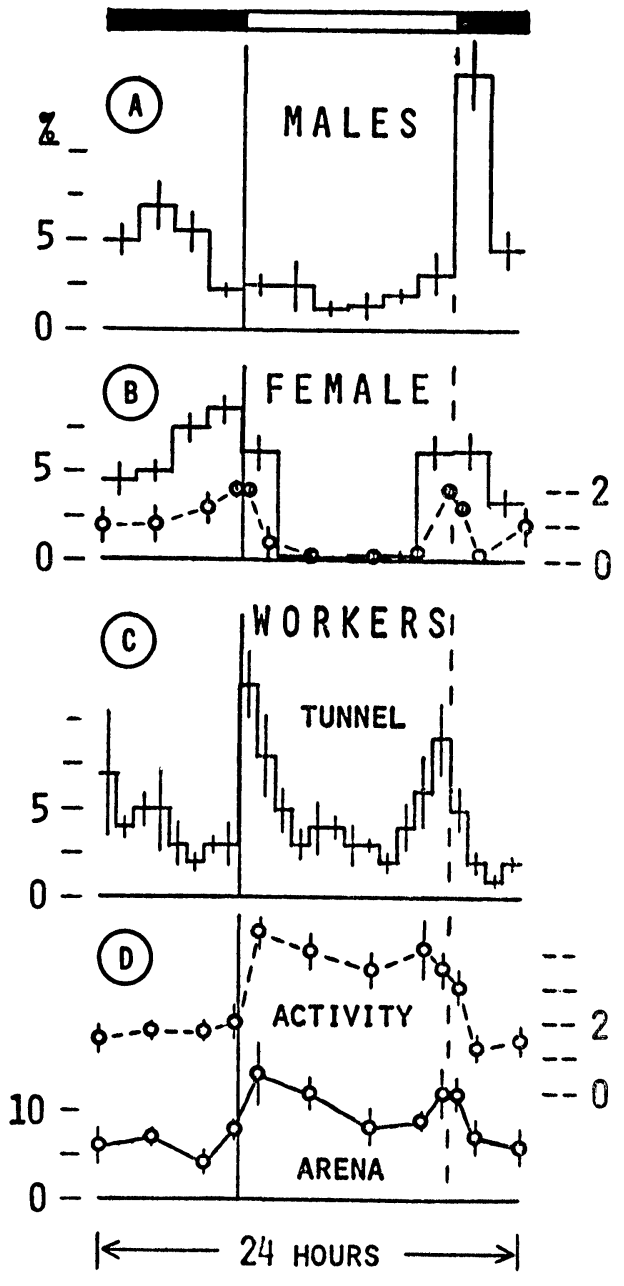


Finally, the ants in the field were observed only for a few days and in only one season; perhaps they differ at other times. However, a predominantly crepuscular-nocturnal timing in the field is supported by observations of WLB made in Costa Rica in 1966 and in the Amazon Basin in 1967 and 1971, and by Hermann and Blum's (I966) statement that they collected Paraponera "in the evenings, just before ants left their nests to forage during the night." In contrast is a very brief statement by Mann (I916): "In habit it is diurnal."

Males, females, and workers were all studied in LD and in DD, each caste in isolation from the others. This permits a comparison of their inherent rhythmicity. In LD (Fig. 5) the males were active at night, especially the first hour, and inactive throughout the light period. The one female was active especially before and after the lights went off and from late night through the first hour of the light. The peaks for the workers were within the light period. In DD (Fig. 3 and 4) there was evidence for persistence of rhythm in the males and the female, but not the workers. Thus there was an interesting contrast in timing between the castes. However, the limited number of specimens studied precludes pressing this conclusion very far.

In the same darkroom the same year, a striking difference in phase relationship was demonstrated between males and workers of another ant, Camponotus clarithorax (McCluskey, 1965). The males were

Fig. 5. Rhythms of males, of female, and of workers in LD, records for all available days combined. Means $\pm S E$ are based on different days as replicates except in (C) where different ants are the replicates. Tunnel count (histograms) and Arena count converted to hourly percentage of 24-hour total before deriving mean, SE, and ANOVA. One-way ANOVA's give $\mathrm{P}<.001$ for each of the six rhythms shown except for Arena $(<.05)$. For the point plots the first count after midnight is repeated. Bar at top indicates light on $12 \mathrm{hr}$ from vertical dawn line (solid) until dusk line (dashed). A) Same group of 3 males as in Fig. $3 ; \mathrm{N}=4-5$ days (Feb. 39); graph in McCluskey (1965) based on same data. B) Same female as in Fig. 3 and 4; Tunnel, $\mathrm{N}=9$ days (Feb, 8-9, Mar. 2-4 \& 8-15); Activity, $N=$ 4-6 days (Mar. 8-15) (activity index as in Fig. 4). Note rise before dawn (ANOVA of last $6 \mathrm{hr}$ : Tunnel, $\mathrm{P}<.01$; Activity, $\mathrm{P}=.05$ ) and before dusk (Tunnel, $\mathrm{P}<.001$; Activity, $\mathrm{P}<.001$ ). C) Three workers, each housed singly in a separate recording assembly; one of the three is based on 1 day of records (Mar. 10-11), another on 2 days (Mar. 30Apr. 1), and the third on 4 days (Mar. 30-Apr. $1 \&$ Apr. 11-12), but only the average was used for each hour where there was more than 1 day of records; thus $\mathrm{N}=3$ ants. $\mathrm{D})$ Same group of 10 workers as in Fig. 4; Activity, $\mathrm{N}=3-4$ days (Mar. 10-15) (activity index as in Fig. 4); Arena, $\mathrm{N}=4-5$ days (Mar. 9-15). 
active only during the first half of the light period, whereas the workers were active only through the night. In Iridomyrmex humilis in LD the males come out only for the last hours of the light period, whereas workers are seen out at all hours (McCluskey, 1963); inside the nest, however, males are active at least throughout the daylight hours (McCluskey, 1965). In Veromessor andrei, the males are active mainly around the dawn in LD (McCluskey, 1958), the peak for the females is then but activity is spread over many hours (McCluskey, 1967), whereas the broad peak for the workers is around dusk with activity spread over many hours (McCluskey, 1963, and unpublished).

The nature of the caste difference in rhythm deserves further study with respect to its import for both comparative and social behavior, as well as for interaction with the natural cyclic environment.

\section{SUMMARY}

Few laboratory studies of circadian rhythms have been made in social insects. Ants from one nest of Paraponera clavata were studied. In the field on Barro Colorado Island they emerged regularly at dusk and apparently foraged until dawn. In an artificial nest in room conditions they displayed striking dawn and dusk peaks of activity and of number out in the arena. In a darkroom in constant temperature and alternating light and dark, they were diurnal rather than crepuscular-nocturnal. In the same conditions a winged female in one counter assembly and a group of three males in another were each nocturnal, the males being especially active the first hour of darkness, and the female active at the first and last ends of the light period as well. Both male and female rhythms persisted in constant darkness, whereas worker rhythms did not perisist, at least in these brief experiments. The nature of the caste difference in rhythm deserves further study.

Collection and culture observations are noted. Foragers in the field return with droplets between their mandibles. Ants tested in the laboratory with sugar solution showed no mouth digestion of sucrose like that in the honeybee.

\section{AcKNowledgements}

This work was done at the Biological Laboratories of Harvard University during the tenure of a postdoctoral fellowship (NSF 49IOI) to ESM. It was supported also by a grant to WLB from the Milton Fund of Harvard University. Special thanks go to $\mathrm{E}$. 
O. Wilson for the free use of his laboratory; he also kindly read the manuscript.

BequaERT, J.

\section{Literature Cited}

1926. Medical and economic entomology. In Medical Report of the Hamilton Rice Seventh Expedition to the Amazon, in Conjunction with the Department of Tropical Medicine of Harvard University 1924-1925, Harvard University Press, Cambridge, Mass., p. 155-257.

Herman , H. R., JR., and Blum, M. S.

1966. The morphology and histology of the hymenopterous poison apparatus. I. Paraponera clavata (Formicidae). Ann. Entomol. Soc. Amer. 59: 397-409.

KavanaU, J. L.

1967. Behavior of captive white-footed mice. Science 155: 1623-39.

ManN, W. M.

1916. The ants of Brazil. Bull. Mus. Comp. Zool. Harvard 60: 397490.

McCluskey, E. S.

1958. Daily rhythms in male harvester and Argentine ants. Science $128: 536-37$.

1963. Rhythms and clocks in harvester and Argentine ants. Physiol. Zool. 36: 273-92.

1964. Field and laboratory rhythms in an ant. Amer. Zoologist 4: 307 (abstract).

1965. Circadian rhythms in male ants of five diverse species. Science 150: 1037-39.

1967. Circadian rhythms in female ants, and loss after mating flight. Comp. Biochem. Physiol. 23 : 665-77.

WEBER, N. A.

1946. Two common ponerine ants of possible economic significance, Ectatomma tuberculatum (Olivier) and E. ruidum Roger. Proc. Entomol. Soc. Wash. 48 : 1-16.

WILSON, E. O.

1962. Chemical communication among workers of the fire ant Solenopsis saevissima (Fr. Smith). I. The organization of mass foraging. Anim. Behav. $10: 134-47$. 

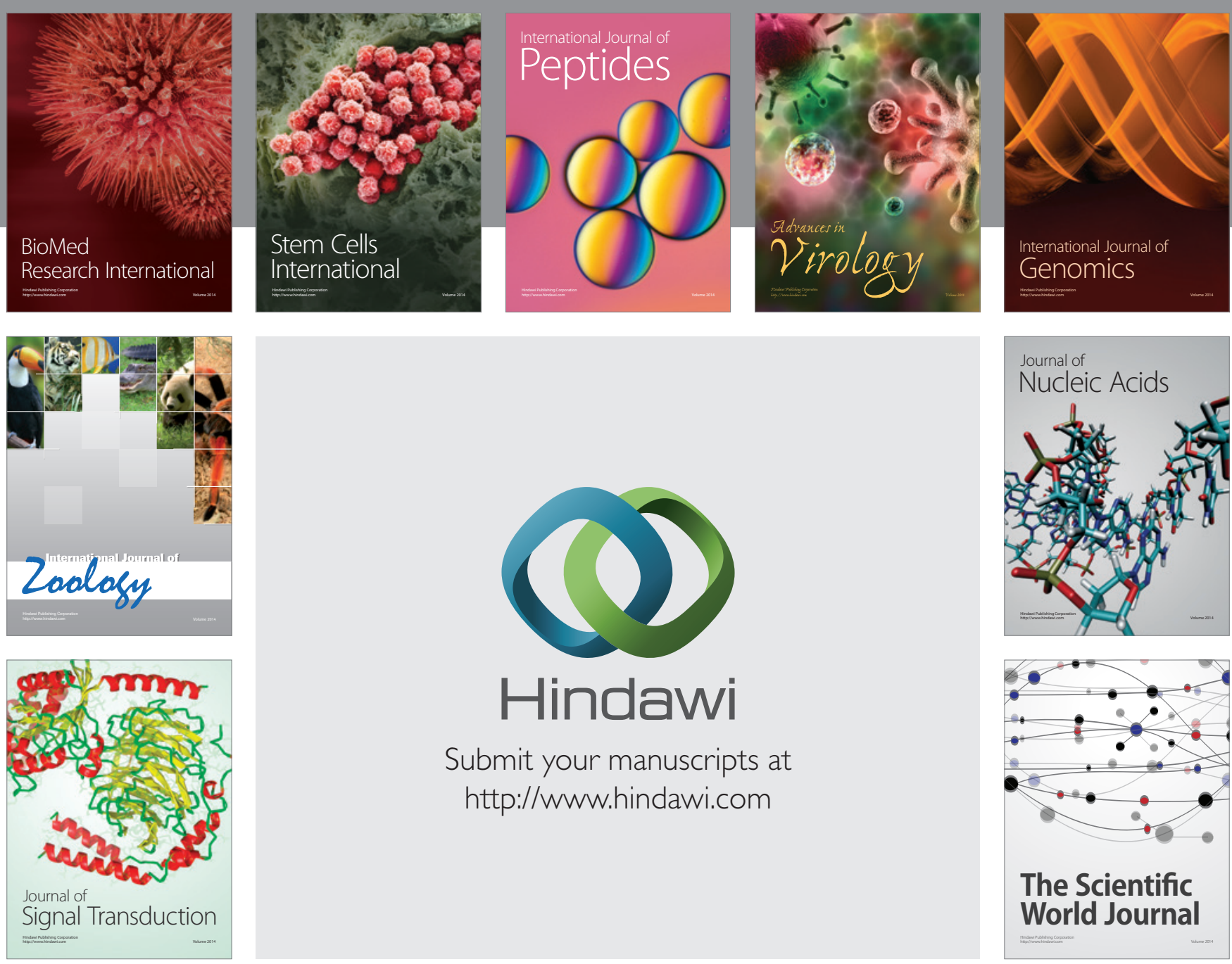

Submit your manuscripts at

http://www.hindawi.com
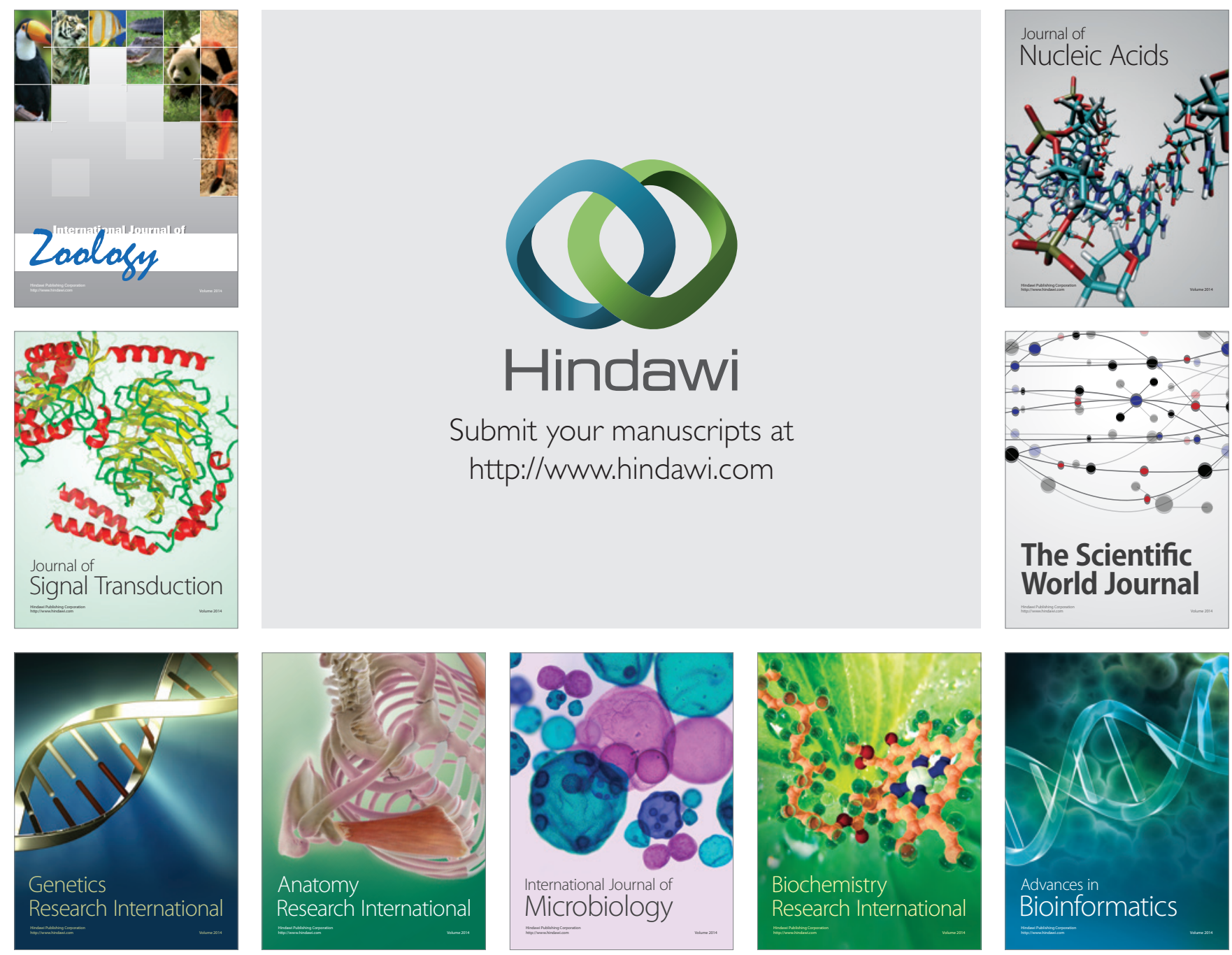

The Scientific World Journal
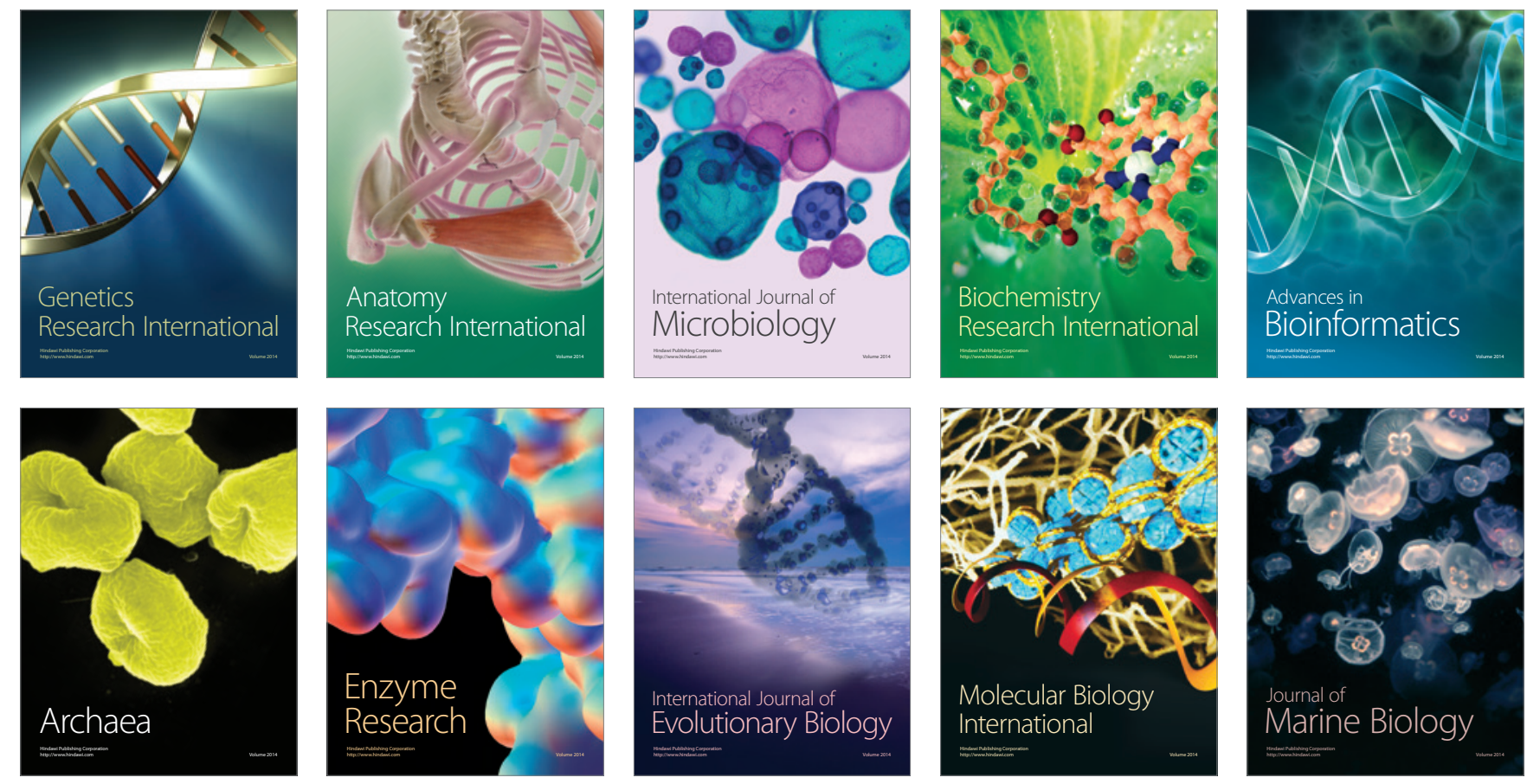